\title{
Gender- and age-related treatment compliance in patients with osteoporosis in Germany
}

\author{
This article was published in the following Dove Press journal: \\ Patient Preference and Adherence \\ 23 November 2016 \\ Number of times this article has been viewed
}

\author{
Peyman Hadji' \\ Louis Jacob ${ }^{2}$ \\ Karel Kostev ${ }^{3}$ \\ 'Department of Bone Oncology, \\ Endocrinology and Reproductive \\ Medicine, Nordwest Hospital, \\ Frankfurt, Germany; ${ }^{2}$ Faculty of \\ Medicine, University of Paris, Paris, \\ France; ${ }^{3}$ Epidemiology, IMS Health \\ GmbH \& Co. Ohg, Darmstädter \\ Landstraße, Frankfurt, Germany
}

\begin{abstract}
Aim: The purpose of this study was to analyze treatment compliance in osteoporotic patients treated with osteoporosis medications in Germany.

Methods: Patients included in the analysis had been diagnosed with osteoporosis with or without fractures and started anti-osteoporotic therapy (bisphosphonates, denosumab, or strontium ranelate) between 2011 and 2014 in a general (GP) or orthopedic practice (OP) setting in Germany. Data pertaining to 6,221 individuals followed in GP and 4,044 individuals followed in OP were analyzed retrospectively. The last follow-up was in December 2015. The main outcome measure was the compliance within the one-year period after the index prescription date. Compliance was measured indirectly and was based on the mean possession ratio (MPR). A multivariate logistic regression model was used to determine the association between MPR (dependent variable) and age, gender, type of practice, type of osteoporosis treatment, therapy frequency, and history of fracture (covariates).

Results: The mean age of the study group was 73.3 years, and $13.2 \%$ of subjects were men. Regarding type of practice, $60.6 \%$ of individuals were followed in GP and $39.4 \%$ in OP. Noncompliance was observed in $55.2 \%$ of the patients. Patients in the age group $\leq 60$ years were at a higher risk of being noncompliant when compared to those in the age group of 61-70 years. Men and patients who received oral drugs were also more likely to be noncompliant than women and patients who received injectable or intravenous drugs. Finally, therapies that were given every three or six months were associated with a decrease in the risk of noncompliance when compared to weekly therapy, whereas daily and monthly treatments were associated with an increased risk.
\end{abstract}

Conclusion: Compliance is insufficient in osteoporotic patients treated with osteoporosis medications.

Keywords: osteoporosis treatment, compliance, fracture, real-world data, Germany

\section{Introduction}

Osteoporosis affects around 200 million patients and causes more than 8.9 million fractures worldwide every year. ${ }^{1}$ One in three women and one in five men over the age of 50 years are estimated to experience osteoporotic fractures. ${ }^{1}$ A recently published epidemiologic study reported that in 2009 , around five million patients $(6.3 \%$ of population) were diagnosed with osteoporosis in Germany, and that the fracture-associated yearly cost exceeded 9 billion euros, underscoring the major impact of this chronic disease on health economics nationwide. ${ }^{1}$

Medications prescribed to patients with osteoporosis usually need to be taken for several years in order to achieve successful outcomes, in particular the prevention of osteoporotic fractures. ${ }^{2-4}$ Unfortunately, one major problem associated with osteoporosis and other chronic disorders is the lack of patient compliance, persistence,
Epidemiology, IMS Health GmbH \& Co.

Ohg, Darmstädter Landstraße 108, 60598

Frankfurt am Main, Germany

Tel +496966044878

Email kkostev@de.imshealth.com 
and adherence. ${ }^{5}$ Compliance is defined as taking drugs as directed; persistence as continuing to take treatments; and adherence as the overall behavior of the patient, of which compliance and persistence are components. ${ }^{6-8}$ A 2012 study based on German real-world data reported that compliance and persistence were insufficient in osteoporotic patients treated with bisphosphonates, strontium ranelate, or parathyroid hormone (PTH). ${ }^{9}$ That same year, another study showed that one-third of osteoporotic women treated with oral bisphosphonates had either poor or very poor compliance. ${ }^{10}$ More recently, mean possession ratio (MPR) was found to be around $64 \%$ in almost 300,000 Hungarian individuals. ${ }^{11}$ In the same analysis, good compliance reduced the risk of fracture, fracture-related hospitalization, and death. ${ }^{11}$

The goal of the present study was to reanalyze treatment compliance in osteoporotic patients treated with osteoporosis medications and followed in general (GP) and orthopedic practices (OP) in Germany between 2011 and 2015.

\section{Methods}

\section{Database}

The Disease Analyzer database (IMS Health) compiles drug prescriptions, diagnoses, and basic medical and demographic data obtained directly and in anonymous format from computer systems used in the practices of general and orthopedic practitioners. ${ }^{12}$ Diagnoses (International Classification of Diseases, Tenth Revision [ICD-10]), prescriptions (Anatomical Therapeutic Chemical classification system), and the quality of reported data are monitored by IMS based on a number of criteria (eg, completeness of documentation and linkage between diagnoses and prescriptions).

In Germany, the sampling methods used for the selection of physicians' practices were appropriate to obtain a representative database of primary care and orthopedic practices. ${ }^{12}$ Prescription statistics for several drugs were very similar to data available from pharmaceutical prescription reports. ${ }^{12}$ The age groups for given diagnoses in Disease Analyzer also agreed well with those in corresponding disease registries. ${ }^{12}$ Finally, the Disease Analyzer database has already been used in studies focusing on osteoporosis. ${ }^{13-15}$

\section{Study population}

For such studies based on anonymous data in Germany no special ethic approval or patient consent is required and hence it was not sought for this study. Patients included in the analysis had been diagnosed with osteoporosis with or without fractures (ICD 10: M80, M81) and started antiosteoporotic therapy (bisphosphonates, denosumab, or strontium ranelate) between 2011 and 2014 in a German GP or OP. The last follow-up was in December 2015. Patients were excluded if they were not followed for at least 365 days after the index date. This exclusion was necessary for the correct calculation of MPR. Patients were also excluded if they were not aged between 40 and 90 years or if the initial prescription was zoledronate. As zoledronate is given once a year, investigations of compliance with this medication are not possible. Ultimately, data pertaining to 6,221 individuals followed in GP and 4,044 individuals followed in OP were analyzed retrospectively (Figure 1).

\section{Study outcome}

The main outcome was compliance during the one-year period after the index prescription date. This result was measured indirectly and was based on the MPR. MPR was calculated as the sum of refills within 365 days after the index date divided by 365 (Figure 2). Patients with an MPR value less than $80 \%$ were considered noncompliant.

\section{Independent variables}

Demographic data included age and gender. Clinical data included type of practices in which patients were followed (GP versus OP), type of osteoporosis drug (oral versus injectable), treatment frequency (daily, weekly, monthly, three-monthly, and six-monthly), and history of fracture prior to the index date.

\section{Statistical analyses}

MPR values and the share of noncompliant patients (MPR $<80 \%$ ) were estimated in the entire population and in specific subgroups. A multivariate logistic regression model was further used to determine the association between MPR (dependent variable) and age, gender, type of practice, type of osteoporosis treatment, therapy frequency, and history of fracture (covariates). $P$-values less than 0.05 were considered to be statistically significant. The analyses were carried out using SAS version 9.3.

\section{Results}

\section{Patient characteristics}

Patient characteristics are displayed in Table 1. The mean age was 73.3 years (standard deviation $[\mathrm{SD}]=9.7$ years), and $13.2 \%$ of subjects were men. Furthermore, $60.6 \%$ of individuals followed were treated in GP and 39.4\% were treated in OP. The proportion of oral and injectable drugs was $82.2 \%$ and $18.8 \%$, respectively. Weekly frequency of treatment was the most common (78.9\%), followed by six-monthly treatment frequency $(9.9 \%)$. Finally, a history of fracture prior to the index date was found in $42.7 \%$ of patients. 


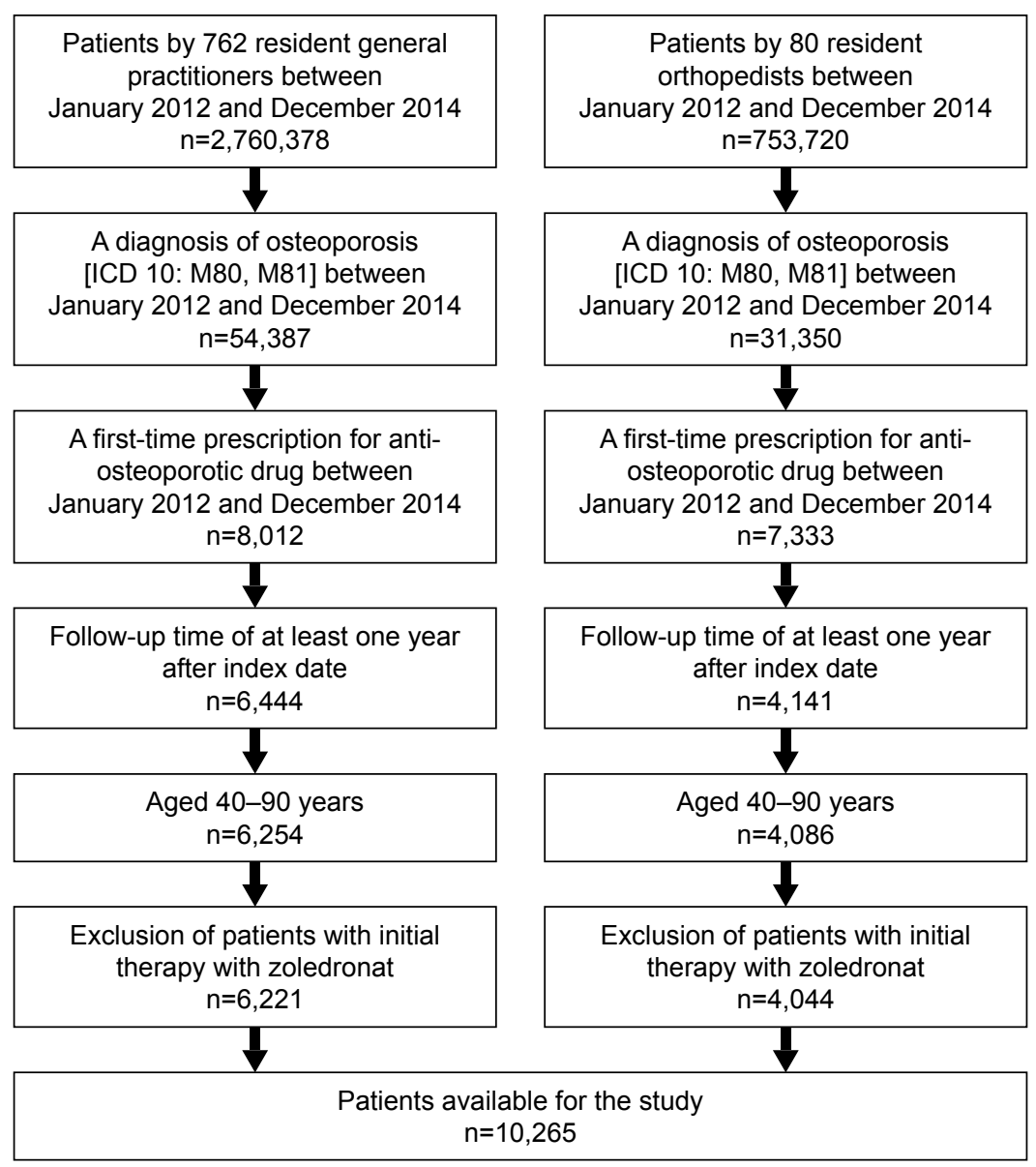

Figure I Flowchart of osteoporotic patients with anti-osteoporotic therapy in general and orthopedic practices in Germany included in this study. Abbreviation: ICD I0, International Classification of Diseases, Tenth Revision.

\section{Compliance in osteoporotic patients treated with osteoporosis medications}

Table 2 displays MPR values and the share of noncompliant individuals (MPR $<80 \%$ ) in the entire population and in specific subgroups. Noncompliance was found in $55.2 \%$ of all patients (MPR $=0.63$ ). This non-compliance decreased with age ( $\leq 60$ years: $58.9 \%, 61-70$ years: $55.6 \%, 71-80$ years $55.2 \%$, and $81-90$ years: $53.1 \%$ ), and was higher in men than in women (59.1\% versus 54.6\%) and in GP than in OP setting (56.5\% versus $53.2 \%)$. Furthermore, noncompliance was much lower with injectable therapy than with oral therapy $(44.1 \%$ versus $57.6 \%)$ but strongly increased with treatment

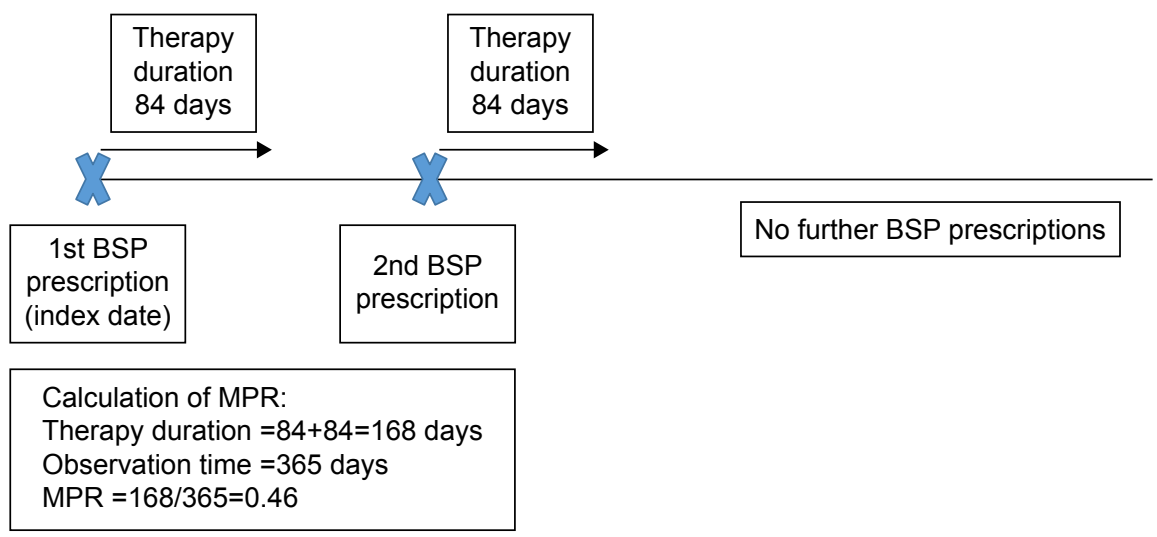

Figure 2 Example of the MPR calculation.

Abbreviations: MPR, mean possession ratio; BSP, Bisphosphonate. 
Table I Baseline characteristics of osteoporotic patients with anti-osteoporotic therapy in general and orthopedic practices in Germany

\begin{tabular}{ll}
\hline Variable & Value \\
\hline $\mathrm{N}$ & 10,265 \\
Age (years); mean (SD) & $73.3(9.7)$ \\
Age $\leq 50(\%)$ & 11.7 \\
Age 5I-60 (\%) & 20.5 \\
Age 6I-70 (\%) & 44.4 \\
Age 7I-80 (\%) & 23.5 \\
Age 8I-90 (\%) & 13.2 \\
Men (\%) & 13.2 \\
Treatment by general practitioners (\%) & 60.6 \\
Treatment by orthopedists (\%) & 39.4 \\
Oral therapy (\%) & 82.2 \\
Injectable therapy (\%) & 18.8 \\
Daily therapy (\%) & 3.6 \\
Weekly therapy (\%) & 78.9 \\
Monthly therapy (\%) & 1.9 \\
Three-monthly therapy (\%) & 5.7 \\
Six-monthly therapy (\%) & 9.9 \\
Fracture prior to the index date (\%) & 42.7 \\
\hline
\end{tabular}

frequency, from $28.1 \%$ in therapies that were administered every six months to $76.3 \%$ in daily therapies. Finally, compliance was higher in patients with a history of fracture than in people without fracture prior to the index date $(45.9 \%$ versus $44.0 \%$ ). The results of the multivariate logistic regression model are shown in Table 3. Patients in the age group $\leq 60$ years were at a higher risk of being noncompliant

Table 2 Compliance with osteoporosis treatment in general and orthopedic practices in Germany

\begin{tabular}{|c|c|c|}
\hline Variable & $\begin{array}{l}\text { MPR } \\
\text { (mean, SD) }\end{array}$ & $\begin{array}{l}\text { Share of } \\
\text { patients with } \\
\text { MPR }<0.80(\%)\end{array}$ \\
\hline All patients & $0.63(0.33)$ & 55.2 \\
\hline Age $\leq 60$ years & $0.61(0.33)$ & 58.9 \\
\hline Age $6 I-70$ years & $0.63(0.33)$ & 55.6 \\
\hline Age $71-80$ years & $0.63(0.33)$ & 55.2 \\
\hline Age $8 I-90$ years & $0.64(0.33)$ & 53.1 \\
\hline Men & $0.60(0.34)$ & 59.1 \\
\hline Women & $0.64(0.33)$ & 54.6 \\
\hline Treatment by general practitioners & $0.62(0.34)$ & 56.5 \\
\hline Treatment by orthopedists & $0.65(0.32)$ & 53.2 \\
\hline Oral therapy & $0.62(0.34)$ & 57.6 \\
\hline Injectable therapy & $0.71(0.28)$ & 44.1 \\
\hline Daily therapy & $0.47(0.33)$ & 76.3 \\
\hline Weekly therapy & $0.61(0.34)$ & 57.6 \\
\hline Monthly therapy & $0.61(0.32)$ & 64.7 \\
\hline Three-monthly therapy & $0.67(0.29)$ & 51.6 \\
\hline Six-monthly therapy & $0.81(0.19)$ & 28.1 \\
\hline Fracture prior to the index date & $0.64(0.33)$ & 54.1 \\
\hline No fracture prior to the index date & $0.62(0.33)$ & 56.0 \\
\hline
\end{tabular}

Abbreviations: MPR, mean possession ratio; SD, standard deviation.
Table 3 Association between noncompliance and predefined risk factors: results of the multivariate logistic regression

\begin{tabular}{|c|c|c|}
\hline Variable & $\begin{array}{l}\text { Odd ratio* } \\
(95 \% \mathrm{Cl})\end{array}$ & $P$-value \\
\hline Age $\leq 60$ versus $6 \mathrm{I}-70$ (years) & $1.24(1.07-1.42)$ & 0.004 \\
\hline Age $7 \mathrm{I}-80$ versus $6 \mathrm{I}-70$ (years) & $1.00(0.90-1.1 \mathrm{I})$ & 0.061 \\
\hline Age $8 I-90$ versus $6 \mathrm{I}-70$ (years) & $0.92(0.81-1.04)$ & 0.969 \\
\hline Men versus women & $1.15(1.02-1.29)$ & 0.019 \\
\hline Therapy by orthopedists versus GP & $1.04(0.95-1.13)$ & 0.398 \\
\hline Oral therapy versus injectable & $1.68(1.51-1.86)$ & $<0.001$ \\
\hline Daily therapy versus weekly & $2.37(1.86-3.02)$ & $<0.001$ \\
\hline Monthly therapy versus weekly & $1.35(1.00-1.81)$ & 0.048 \\
\hline Three-monthly therapy versus weekly & $0.79(0.67-0.93)$ & 0.005 \\
\hline Six-monthly therapy versus weekly & $0.29(0.25-0.33)$ & $<0.001$ \\
\hline Fracture versus no fracture & $0.95(0.87-1.03)$ & $0.17 \mid$ \\
\hline
\end{tabular}

Note: *Adjusted for age, gender, physician practice (general or orthopedic practice), type of therapy (oral or injectable), therapy frequency (daily, weekly, monthly, threemonthly, or six-monthly), and history of fracture prior to the index date.

Abbreviations: $\mathrm{Cl}$, confidence interval; GP, general practice.

when compared to those in the age group of $61-70$ years (odds ratio $[\mathrm{OR}]=1.24$ ). No significant differences were found for the age groups of 71-80 or 81-90 years compared with that of 61-70 years. Men and patients prescribed oral drugs were also more likely to be noncompliant than women $(\mathrm{OR}=1.15)$ and patients prescribed injectable drugs $(\mathrm{OR}=1.68)$. Finally, six-monthly and three-monthly therapies were associated with a decrease in the risk of noncompliance when compared to weekly therapy (OR $=0.29$ and 0.79 , respectively). In contrast, daily and monthly treatments led to an increased risk of noncompliance ( $\mathrm{OR}=2.37$ and 1.35 , respectively).

\section{Discussion}

Compliance with osteoporosis treatment was low in the present retrospective study, which included 10,265 patients either followed in GP or in OP setting. Patients aged 60 years or younger were significantly less compliant than those aged between 61 and 70 years. No significant differences were found for the age groups of 71-80 or 81-90 years compared with that of 61-70 years. Men were also at a higher risk of noncompliance than women. Individuals receiving an injectable therapy exhibited a higher rate of compliance compared to those receiving an oral therapy. Finally, patients on threeand six-monthly administrations were more compliant than those on weekly therapies. We also found that people with monthly treatments were more likely to be noncompliant than those with weekly treatments.

Osteoporosis is considered an inevitable consequence of aging, as well as a consequence of clinical risk factors and treatment side effects, such as glucocorticoid use, which have a major impact on morbidity and mortality throughout 
the world. ${ }^{1}$ Several randomized controlled trials have found that the use of bisphosphonates for 3-4 years reduces the risk of developing nonvertebral and vertebral fractures in women with osteoporosis. ${ }^{3,4}$ To translate this effect into clinical practice, relevant prescribed drugs must be taken on a long-term basis. As a result, one important problem associated with osteoporosis treatment is the lack of compliance of patients affected by this chronic disease., ${ }^{9,16}$ One must bear in mind that compliance is a complex process that is influenced by a variety of factors related to both patients and physicians. ${ }^{17}$ In a recently reported French study, only $65.5 \%$ of osteoporotic women considered themselves compliant, and the correlation between patient and physician perceptions of compliance was weak. ${ }^{16}$ The highest compliance was found in women treated with monthly bisphosphonates (79.7\%), and the lowest one in people receiving hormone replacement therapy (50.0\%). Furthermore, compliance was higher with monthly than with daily therapies. In line with these findings, Kishimoto and Maehara showed that a monthly regimen has better treatment compliance when compared with weekly and daily regimens. ${ }^{18}$ These results suggest that compliance and potential convenience are inversely related to the administration frequency of a given treatment. The present study corroborates this hypothesis, as patients on three- and six-monthly therapies showed higher rates of compliance compared to those on weekly therapies, whereas individuals on daily administrations were even less compliant. By contrast, we also found that people with monthly treatments were more likely to be noncompliant than those with weekly treatments. This finding must be discussed with caution since the multivariate logistic regression model was not adjusted for potential confounders, which may have a significant impact. With this in mind, a US study published in 2009 suggested that patient compliance and persistence are similar for monthly ibandronate and weekly risedronate dosing. ${ }^{19}$ Therefore, even if the difference in compliance is well known between daily and monthly administrations of osteoporosis treatment, the difference between weekly and monthly therapies remains controversial.

Few authors in Europe have studied compliance with osteoporosis drugs in real-world settings. A 2012 analysis consisting of more than 265,000 individuals from a representative longitudinal database developed by IMS Health (LRx) has shown that persistence and compliance were insufficient during the time period of 2007-2009. ${ }^{9}$ The mean MPR ranged from $46 \%$ (strontium ranelate) to $70 \%$ (ibandronate $3 \mathrm{mg}$ intravenous [IV]). ${ }^{9}$ Based on the results of this study, it seems that compliance may be influenced by the convenience of packaging, route of administration, and tolerability. ${ }^{9,20,21}$ The suboptimal compliance associated with given drugs may compromise the prevention of osteoporotic fractures. ${ }^{22,23}$ Also in 2012, Hadji et al estimated that one-third of 4,147 women with osteoporosis who took oral bisphosphonates displayed either poor (22.7\%) or very poor compliance $(11.0 \%) .{ }^{10}$ Kaplan-Meier analyses further showed that the estimated two-year fracture rates were significantly different between compliant and noncompliant individuals (11.9\% versus $15.0 \%) .{ }^{10}$ More recently, Lakatos et al reported that in 296,300 Hungarian women, both persistence and compliance were higher with parenteral and half-yearly therapies than with oral and daily/weekly/monthly therapies. ${ }^{11}$ Corroborating previous results, good compliance significantly reduced the risk of fracture $(\mathrm{OR}=0.77)$, fracture-related hospitalization $(\mathrm{OR}=0.72)$, and death $(\mathrm{OR}=0.57)$. In line with the findings of Lakatos et al, ${ }^{11}$ the present retrospective study found that injectable and IV drugs had a positive effect on compliance when compared to oral drugs. This finding reflects the fact that IV drugs may involve fewer side effects than oral therapies, particularly gastrointestinal side effects, which are very common in individuals with osteoporosis who are being treated with oral bisphosphonates. ${ }^{24}$ It is also possible that a medication is less likely to be missed when it is an IV injection rather than a pill.

Finally, men and younger patients were at a higher risk of noncompliance than women and older individuals. These associations have been the center of controversial literature in past decades. In an Israeli study of 178 postmenopausal women, there was a negative association between age and compliance. ${ }^{25}$ More recently, Solomon et al showed in a study performed in Pennsylvania that women had a 1.16-fold increased chance of being compliant when compared to men, whereas age was negatively associated with this outcome. ${ }^{26}$ In 2007, a Canadian meta-analysis also estimated that women were less likely to be noncompliant than men. ${ }^{27}$ In contrast, no clear effect of age was found on patient adherence. ${ }^{27}$ Finally, in 2015, Thorsteinsson et al estimated in a Danish national register-based cohort study that gender and age have no impact on compliance in osteoporotic patients treated with $\mathrm{PTH}{ }^{28}$ Although these various analyses are subject to major differences, which could potentially explain the discrepancy in their findings, one has to remember that numerous studies have discovered gender and age differences in compliance, persistence, and adherence in patients affected by chronic conditions. ${ }^{29-31}$

The present study showed several factors which may influence the compliance with osteoporotic treatments. 
Further studies are necessary to evaluate the potential reasons for noncompliance in this therapeutic area. One possible explanation may be the gastrointestinal side effects. ${ }^{24}$

Our study had several limitations. First, no information was available regarding the procedure by which osteoporosis diagnoses were assessed. Second, no detailed documentation on treatment side effects was available. Moreover, data on the socioeconomic status and lifestyle-related risk factors were also not available. The strength of this study was the inclusion of large number of patients and using multivariable regression analysis.

\section{Conclusion}

Compliance was insufficient in osteoporotic patients treated with bisphosphonates, denosumab, and strontium ranelate in Germany. While several risk factors for noncompliance were identified, further studies are needed to obtain a better understanding of their association with compliance and their potential impact on clinical outcomes related to osteoporosis. There is a need for the improvement of patient compliance. For example, patient education or the availability of structured disease programs could influence therapy compliance in osteoporotic patients.

\section{Disclosure}

The authors report no conflicts of interest in this work.

\section{References}

1. Facts and Statistics. International Osteoporosis Foundation. Available from: https://www.iofbonehealth.org/facts-statistics. Accessed July 18, 2016.

2. Höer A, Seidlitz C, Gothe H, et al. Influence on persistence and adherence with oral bisphosphonates on fracture rates in osteoporosis. Patient Prefer Adherence. 2009;3:25-30.

3. Black DM, Bauer DC, Schwartz AV, Cummings SR, Rosen CJ. Continuing bisphosphonate treatment for osteoporosis - for whom and for how long? N Engl J Med. 2012;366(22):2051-2053.

4. Hadji P, Papaioannou N, Gielen E, et al. Persistence, adherence, and medication-taking behavior in women with postmenopausal osteoporosis receiving denosumab in routine practice in Germany, Austria, Greece, and Belgium: 12-month results from a European non-interventional study. Osteoporos Int. 2015;26(10):2479-2489.

5. Hadji P, Klein S, Häussler B, et al. The bone evaluation study (BEST): patient care and persistence to treatment of osteoporosis in Germany. Int J Clin Pharmacol Ther. 2013;51(11):868-872.

6. Dezii CM. Persistence with drug therapy: a practical approach using administrative claims data. Manag Care. 2001;10(2):42-45.

7. Andrade SE, Kahler KH, Frech F, Chan KA. Methods for evaluation of medication adherence and persistence using automated databases. Pharmacoepidemiol Drug Saf. 2006;15(8):565-574; discussion 575-577.

8. Hadji P. Improving compliance and persistence to adjuvant tamoxifen and aromatase inhibitor therapy. Crit Rev Oncol Hematol. 2010;73(2): $156-166$.

9. Ziller V, Kostev K, Kyvernitakis I, Boeckhoff J, Hadji P. Persistence and compliance of medications used in the treatment of osteoporosis analysis using a large scale, representative, longitudinal German database. Int J Clin Pharmacol Ther. 2012;50(5):315-322.
10. Hadji P, Claus V, Ziller V, Intorcia M, Kostev K, Steinle T. GRAND: the German retrospective cohort analysis on compliance and persistence and the associated risk of fractures in osteoporotic women treated with oral bisphosphonates. Osteoporos Int. 2012;23(1):223-231.

11. Lakatos P, Takács I, Marton I, et al. A retrospective longitudinal database study of persistence and compliance with treatment of osteoporosis in Hungary. Calcif Tissue Int. 2016;98(3):215-225.

12. Becher H, Kostev K, Schröder-Bernhardi D. Validity and representativeness of the "Disease Analyzer" patient database for use in pharmacoepidemiological and pharmacoeconomic studies. Int J Clin Pharmacol Ther. 2009;47(10):617-626.

13. Jacob L, Dreher M, Kostev K, Hadji P. Increased treatment persistence and its determinants in women with osteoporosis with prior fracture compared to those without fracture. Osteoporos Int. 2016;27(3):963-969.

14. Drosselmeyer J, Rapp MA, Hadji P, Kostev K. Depression risk in female patients with osteoporosis in primary care practices in Germany. Osteoporos Int. 2016;27(9):2739-2744.

15. Jacob L, Hadji P, Kostev K. The use of proton pump inhibitors is positively associated with osteoporosis in postmenopausal women in Germany. Climacteric. 2016;19(5):478-481.

16. Huas D, Debiais F, Blotman F, et al. Compliance and treatment satisfaction of post menopausal women treated for osteoporosis. Compliance with osteoporosis treatment. BMC Womens Health. 2010;10:26.

17. Brod M, Stewart AL, Sands L, Walton P. Conceptualization and measurement of quality of life in dementia: the dementia quality of life instrument (DQoL). Gerontologist. 1999;39(1):25-35.

18. Kishimoto H, Maehara M. Compliance and persistence with daily, weekly, and monthly bisphosphonates for osteoporosis in Japan: analysis of data from the CISA. Arch Osteoporos. 2015;10:231.

19. Gold DT, Trinh H, Safi W. Weekly versus monthly drug regimens: 1-year compliance and persistence with bisphosphonate therapy. Curr Med Res Opin. 2009;25(8):1831-1839.

20. Carr AJ, Thompson PW, Cooper C. Factors associated with adherence and persistence to bisphosphonate therapy in osteoporosis: a crosssectional survey. Osteoporos Int. 2006;17(11):1638-1644.

21. Kertes J, Dushenat M, Vesterman JL, Lemberger J, Bregman J, Friedman N. Factors contributing to compliance with osteoporosis medication. Isr Med Assoc J. 2008;10(3):207-213.

22. Caro JJ, Ishak KJ, Huybrechts KF, Raggio G, Naujoks C. The impact of compliance with osteoporosis therapy on fracture rates in actual practice. Osteoporos Int. 2004;15(12):1003-1008.

23. Siris ES, Selby PL, Saag KG, Borgström F, Herings RM, Silverman SL. Impact of osteoporosis treatment adherence on fracture rates in North America and Europe. Am J Med. 2009;122(2 Suppl):S3-S13.

24. Kennel KA, Drake MT. Adverse effects of bisphosphonates: implications for osteoporosis management. Mayo Clin Proc. 2009;84(7):632-637.

25. Segal E, Tamir A, Ish-Shalom S. Compliance of osteoporotic patients with different treatment regimens. Isr Med Assoc J. 2003;5(12):859-862.

26. Solomon DH, Avorn J, Katz JN, et al. Compliance with osteoporosis medications. Arch Intern Med. 2005;165(20):2414-2419.

27. Papaioannou DA, Kennedy CC, Dolovich L, Lau E, Adachi JD. Patient adherence to osteoporosis medications: problems, consequences and management strategies. Drugs Aging. 2007;24(1):37-55.

28. Thorsteinsson AL, Vestergaard P, Eiken P. Compliance and persistence with treatment with parathyroid hormone for osteoporosis. A Danish national register-based cohort study. Arch Osteoporos. 2015;10:35.

29. Babwah F, Baksh S, Blake L, et al. The role of gender in compliance and attendance at an outpatient clinic for type 2 diabetes mellitus in Trinidad. Rev Panam Salud Pública. 2006;19(2):79-84.

30. Jacob L, Hadji P, Kostev K. Age-related differences in persistence with bisphosphonates in women with metastatic breast cancer. $J$ Bone Oncol. 2016;5(2):63-66.

31. Calabria S, Cinconze E, Rossini M, et al. Adherence to alendronic or risedronic acid treatment, combined or not to calcium and vitamin D, and related determinants in Italian patients with osteoporosis. Patient Prefer Adherence. 2016;10:523-530. 
Patient Preference and Adherence

Dovepress

\section{Publish your work in this journal}

Patient Preference and Adherence is an international, peer-reviewed, open access journal that focuses on the growing importance of patient preference and adherence throughout the therapeutic continuum. Patient satisfaction, acceptability, quality of life, compliance, persistence and their role in developing new therapeutic modalities and compounds to optimize

Submit your manuscript here: http://www.dovepress.com/patient-preference-and-adherence-journ clinical outcomes for existing disease states are major areas of interest for the journal. This journal has been accepted for indexing on PubMed Central The manuscript management system is completely online and includes a very quick and fair peer-review system, which is all easy to use. Visit http://www. dovepress.com/testimonials.php to read real quotes from published authors. 